\title{
A Systematic Needs Assessment for Point-of- Care Ultrasound in Internal Medicine Residency Training Programs
}

By Kim Lewis, MD, Meghan McConnell, BSc, PhD, Khalid Azzam, MD

\begin{abstract}
About the Authors:
Kim Lewis is a third-year resident in internal medicine at McMaster University in Hamilton, ON. Meghan McConnell is an assistant professor in the Department of Innovation in Medical Education; Department of Anesthesiology and Pain Medicine at the University of Ottawa, Ottawa, ON. Khalid Azzam is with the Department of Medicine, Division of General Internal Medicine, McMaster University, Hamilton, ON. Correspondence may be directed to azzamk@momaster.ca
\end{abstract}

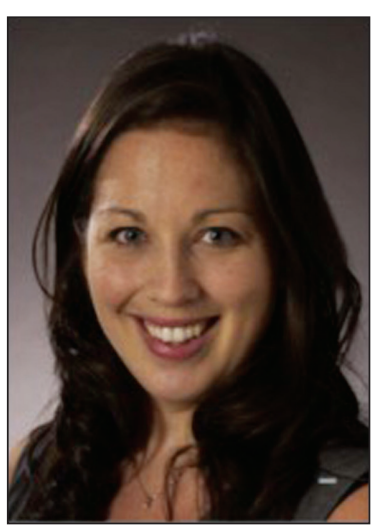

Kim Lewis

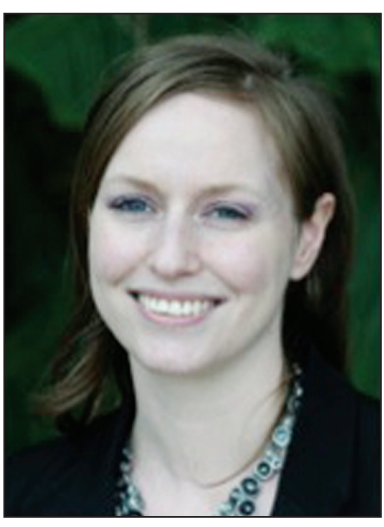

Meghan McConnell

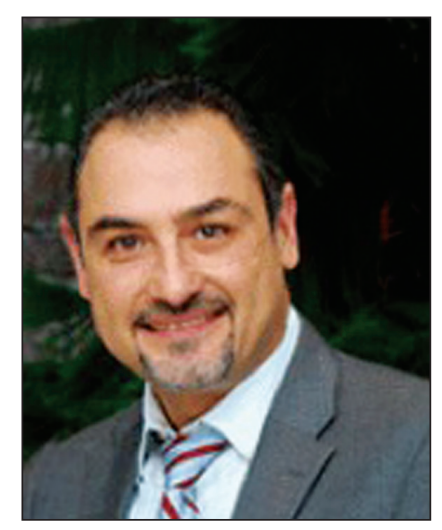

Khalid Azzam

\begin{abstract}
Background: Point-of-Care Ultrasound (PoCUS) is an ultrasound examination performed by the clinician to answer a question or guide a procedure. Few Internal Medicine (IM) programs teach a formal PoCUS curriculum. The objective of this study is to conduct a systematic needs assessment for the introduction of a PoCUS curriculum to an IM program.

Methods: A survey was distributed to all IM staff and residents. Participants rated their comfort, training, and use of PoCUS. Descriptive statistics were calculated using SPSS software.

Results: Participants self-identified as "neutral" on comfort for using PoCUS for diagnostic applications and many lacked formal diagnostic training (9.7\% in residents vs. $32 \%$ in staff, $\chi^{2}=10.5, P=0.002$ ). Despite this inexperience, $26.9 \%$ of residents use PoCUS for diagnostic applications.

Conclusion: A third of residents are using PoCUS despite a lack in formal training, suggesting that PoCUS should be introduced to the IM curriculum.

\section{Résumé}

Contexte : L'échographie ciblée en médecine d'urgence (ÉCMU) est un examen échographique que pratique le clinicien pour répondre à une question ou orienter une intervention. Peu de programmes en médecine interne (MI) offrent un curriculum en ÉCMU. La présente étude vise à obtenir une évaluation systématique des besoins en vue de mettre en place un curriculum en ÉCMU dans un programme de MI.

Méthodologie : Un sondage a été réalisé auprès de l’ensemble du personnel enseignant et des résidents en MI. Les participants ont évalué leur formation et leur degré de confort au regard
\end{abstract}


de l'ÉCMU, ainsi que l'usage qu'ils font de cette technologie. Des statistiques descriptives ont par la suite été calculées à l’aide du progiciel de statistiques SPSS.

Résultats : Les participants ont déclaré se sentir plutôt « neutres » quant à leur aisance à utiliser l'ÉCMU à des fins diagnostiques et nombre d'entre eux manquaient de formation officielle en la matière $\left(9,7 \%\right.$ chez les résidents et $32 \%$ chez le personnel enseignant, $\left.\chi^{2}=10,5 ; P=0,002\right)$. Malgré ce manque de connaissances, $26,9 \%$ des résidents disent utiliser l'ÉCMU à des fins diagnostiques.

Conclusion : Un tiers des résidents utilisent l'ÉCMU malgré un manque de formation officielle. Cette constatation nous indique qu'il y a lieu d'ajouter l'ÉCMU au curriculum de MI.

Point-of-Care Ultrasound (PoCUS) is a limited ultrasound (US) examination performed and interpreted by the clinician at the bedside. PoCUS has a multitude of applications. It be used to guide invasive procedures, and is becoming the standard of care for select procedures such as central line insertion as it reduces the number of attempts and complications. ${ }^{1-3}$ PoCUS has also been found to supplement the physical exam in certain situations. For example, using the jugular venous pressure as a surrogate for right atrial pressure has an accuracy that ranges from 13 to $84 \%$ and has a large inter-rater reliability. ${ }^{4-6}$ Using PoCUS to measure the inferior vena cava collapsibility and diameter as a surrogate for fluid status is sensitive, specific, and has minimal inter-rater variability.,

PoCUS is becoming a required competency in many residency programs. The Canadian Association of Emergency Physicians issued a position statement in 2006 that strongly supported the incorporation of PoCUS training into emergency residency programs and in 2008, it was officially introduced as a Royal College competency. ${ }^{8-10}$ This lagged behind the United States where PoCUS became part of their core curriculum in $1996 .{ }^{11}$ The American Board of Anesthesiology also mandates that PoCUS be part of their core competencies for certain diagnostics and procedures. ${ }^{12}$

Despite gaining popularity and evidence supporting the use of PoCUS, few Internal Medicine (IM) residency programs in Canada are yet to implement a well-rounded PoCUS curriculum. To date, there has never been an assessment of IM staff and resident's current PoCUS training, comfort, and utilization. The objective of this study is to conduct a systematic needs assessment by means of a survey to gauge the interest and necessity for implementation of a PoCUS curriculum in an IM program.

\section{Methods}

The survey was developed by the physician investigators and the following points were targeted:

- The relevant demographic data including position as staff or resident.
- The number of people who are currently using PoCUS for clinical assessments, diagnostic applications, or procedural guidance and their comfort level in doing so?

- The number of people who are trained in PoCUS?

- Do staff and residents want a PoCUS curriculum to be introduced to the IM residency program?

- If implemented, which diagnostic and US guided procedures should be taught to trainees?

- The logistics behind US training including duration of training, who should be providing the training, and when should the training be administered.

The complete 19 question survey is available in the Appendix. There were 4 questions examining comfort with PoCUS, 1 question examining prior PoCUS training, 6 questions looking at curriculum design, 7 questions examining general attitudes towards PoCUS, and 1 question assessing demographics. The McMaster Internal Medicine Research Committee approved the survey. The survey was piloted by 2 residents and then distributed to all McMaster general IM staff physicians and core IM residents online. The survey was available through Survey Monkey from August $22^{\text {nd }}, 20015$ to November $23^{\text {rd }}, 2015$. Participants were assured that their responses would be anonymous.

Survey data was entered into Microscoft Excel and descriptive statistics, including means and standard deviations were calculated using SPSS software. Differences between residents and staff were analyzed using independent $t$ tests or chi-squared using SPSS. Statistical significance was set at $95 \%$ confidence $(p<0.05)$.

\section{Results}

Ninety-three of 109 (85\%) residents and 40 of 83 (43\%) IM staff completed the survey. The overall response rate was $69 \%$. Residents and staff were asked to rate their comfort using PoCUS for both clinical assessment and procedural guidance on a likert scale ( $1=$ 'extremely comfortable', 2 = 'comfortable', $3=$ 'neutral', 4 = 'uncomfortable', and $5=$ extremely 'uncomfortable'). Residents and staff reported neutral comfort using PoCUS for clinical assessment, 3.9 (1.0) and 3.5 (1.3), respectively, mean 
(SD), $p=0.26$ ). Similarly, both residents 2.8 (1.1) and staff 3.0 (1.6) were equally comfortable using PoCUS for procedural guidance $(p=0.36$ ).

Respondents were asked to identify barriers to using PoCUS in clinical practice (Table 1). Both residents and staff reported a lack of comfort with the acquisition of appropriate ultrasound images ( $48 \%$ and $43 \%$, respectively) and the interpretation of the images once acquired ( $57 \%$ of residents and $43 \%$ of staff). Time constraints, poor US availability, and no knowledgeable colleague to review with were also indicated as roadblocks (Table 1).

Table 1. Barriers Identified to using Point-of-Care Ultrasound in Clinical Practice for Both Staff and Residents as Expressed by Percentage (SD)

\begin{tabular}{|c|c|c|}
\hline & $\begin{array}{c}\text { Resident Response } \\
\text { Percent }(\%) \pm \text { Standard Deviation }\end{array}$ & $\begin{array}{c}\text { Staff Response } \\
\text { Percent }(\%) \pm \text { Standard Deviation }\end{array}$ \\
\hline Not comfortable with image acquisition & $48 \pm 0.5$ & $43 \% \pm 0.5$ \\
\hline Unsure of how to interpret images & $57 \pm 0.5$ & $43 \% \pm 0.5$ \\
\hline No ultrasound available & $27 \pm 0.4$ & $30 \% \pm 0.5$ \\
\hline $\begin{array}{l}\text { No knowledgeable colleague to review images with } \\
\text { if you are unsure }\end{array}$ & $32 \pm 0.4$ & $30 \% \pm 0.5$ \\
\hline Time constraints & $25 \pm 0.4$ & $30 \pm 0.5$ \\
\hline
\end{tabular}

Significantly more residents than staff have received informal training in PoCUS guided procedures $(79.3 \%$ of residents and $60.0 \%$ of staff, $p=0.02)$ and diagnostic applications $(58.1 \%$ of residents and $40.0 \%$ staff, $p=0.04$ ). $52 \%$ of residents and $40.0 \%$ of staff have previous formal training in PoCUS guided procedures $\left(\chi^{2}=1.5, p=0.83\right)$. Significantly more staff have formal training in diagnostic applications of PoCUS than residents $(9.7 \%$ of residents and $32.5 \%$ of staff, $p=0.02$ ) (Table 2). Despite the lack of formal training, $26.9 \%$ of residents and $30 \%$ of staff use PoCUS to aid clinical decision making ( $p=0.43$ ).

Attitudes towards PoCUS were assessed though participants ranking their level of agreement to statements on a 5-point likert scale ( $1=$ strongly agree, 5 = strongly disagree). After accounting for making multiple comparisons, there were no significant differences in residents' and staffs' attitudes towards PoCUS (Table 3). Overall, both residents and staff agreed that PoCUS improves patient safety (resident 1.77 [0.9], staff 2.15[0.1]), is an important tool to guide invasive procedures, $1.41(0.7)$ and 1.53 (0.8), respectively, and should be implemented at McMaster for the IM residents, $1.65(0.8)$ and $1.47(0.8)$, respectively. There was a trend for staff to have more positive attitudes 2.70 (3.1) towards PoCUS as an adjunct to the physical exam than residents 3.48 (5.6), although this difference failed to reach significance.

Table 2. Percentage of Both Staff and Residents that Have Had Either Previous Informal or Formal Diagnostic or Procedural Point of Care Ultrasound Training

\begin{tabular}{|l|c|c|c|c|}
\multicolumn{2}{c}{} & \multicolumn{2}{c}{$\begin{array}{c}\text { Previous PoCUS } \\
\text { Procedural Training }\end{array}$} & \multicolumn{2}{c}{$\begin{array}{c}\text { Previous PoCUS } \\
\text { Diagnostic Training }\end{array}$} \\
& Informal Training & Formal Training & $58.1 \%$ & Formal Training \\
\hline Resident & $79.3 \%$ & $51.6 \%$ & $40.0 \%$ & $9.7 \%$ \\
\hline Staff & $60.0 \%$ & $40.0 \%$ & 0.04 & $32.5 \%$ \\
\hline $\boldsymbol{P}$ value & 0.02 & 0.83 & 0.002 \\
\hline
\end{tabular}

Table 3. Mean Scores to Assess Attitudes Towards Point-of-Care Ultrasound Expressed as an Agreement with Statements on A 5-Point Likert Scale

\begin{tabular}{|c|c|c|c|}
\hline Statement & Resident (mean \pm SD) & Staff (mean \pm SD) & P Value \\
\hline PoCUS is an Important Adjunct to the Physical Exam & $3.47 \pm 5.6$ & $2.70 \pm 3.1$ & 0.412 \\
\hline PoCUS is an Important Adjunct for Invasive Procedures & $1.41 \pm 0.8$ & $1.53 \pm 0.8$ & 0.45 \\
\hline PoCUS Improves Patient Safety and outcomes & $1.77 \pm 0.9$ & $2.15 \pm 0.9$ & 0.03 \\
\hline $\begin{array}{l}\text { PoCUS Training Should be Introduced to the IM Residency } \\
\text { Program at McMaster }\end{array}$ & $1.47 \pm 0.8$ & $1.65 \pm 0.83$ & 0.26 \\
\hline
\end{tabular}


Most staff and residents also felt that given the opportunity, PoCUS may be used a few times per week on a scale where $1=$ everyday, $2=$ a few times per week, $3=$ a few times per month, $4=\mathrm{a}$ few times per year and $5=$ never (resident 2.11 [.07], staff 2.20 [1.1], $p=0.6)$. When asked to identify who should teach PoCUS to trainees, both staff and residents believed that IM, anesthesia or emergency staff should be the instructors of the curriculum relative to radiologists or ultrasound technicians (Figure 1). Residents and staff also agreed that the total number of hours dedicated to PoCUS training should be more than 10 hours (Figure 2) and it should be administered during academic half day.

Staff and residents were asked to pick the top 5 PoCUS guided procedures that should be taught (Figure 3). 100\% of staff thought that central line (internal jugular, subclavian, and femoral) insertion should be included in the curriculum and $62 \%$ of the residents also agreed. Thoracentesis (98\% of staff and $76 \%$ of residents), paracentesis (93\% of staff and $66 \%$ of residents), and lumbar puncture (63\% of staff and $59 \%$ of residents) were also commonly selected. Residents felt that arthrocentesis should

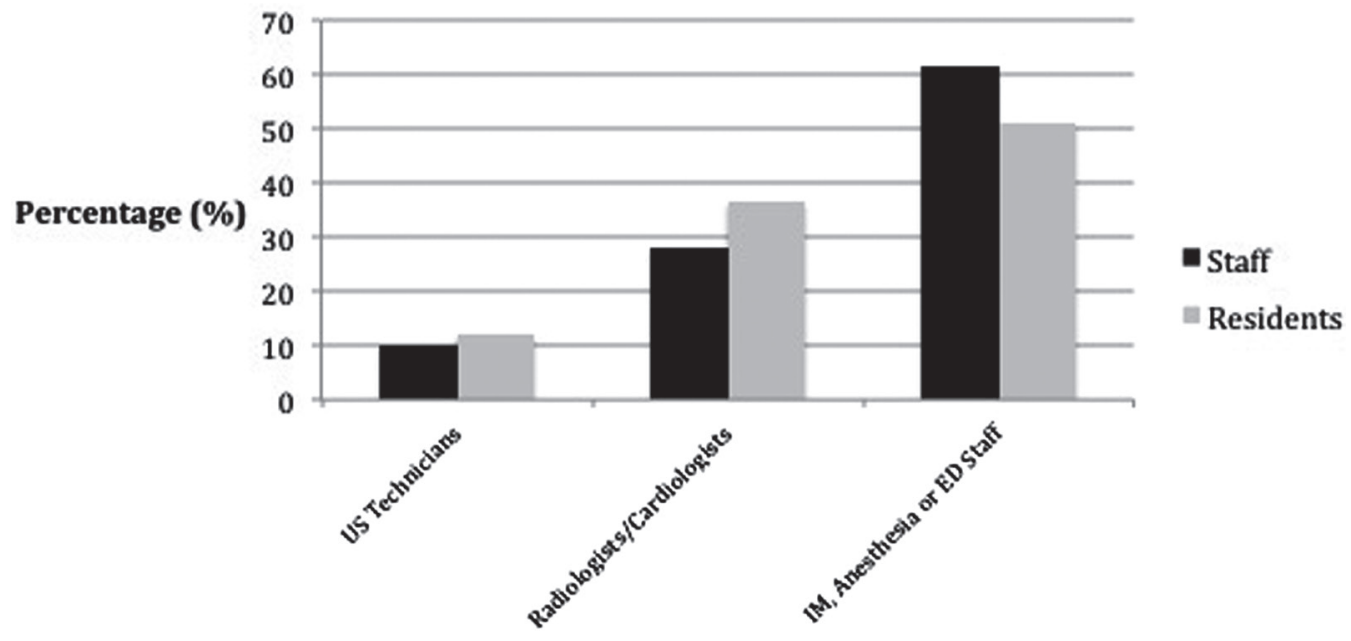

Options for Trainers

Figure 1. When asked who should be instructing the PoCUS training, the majority of both staff and residents thought that an IM, ED or Anesthesia staff would be most appropriate $(61.5 \%$ and $51.5 \%$, respectively, $p=0.481)$ compared to radiologists/cardiologists $(28.2 \%, 36.7 \%$, respectively) or US technicians ( $10.3 \%$ and $12.2 \%$, respectively).

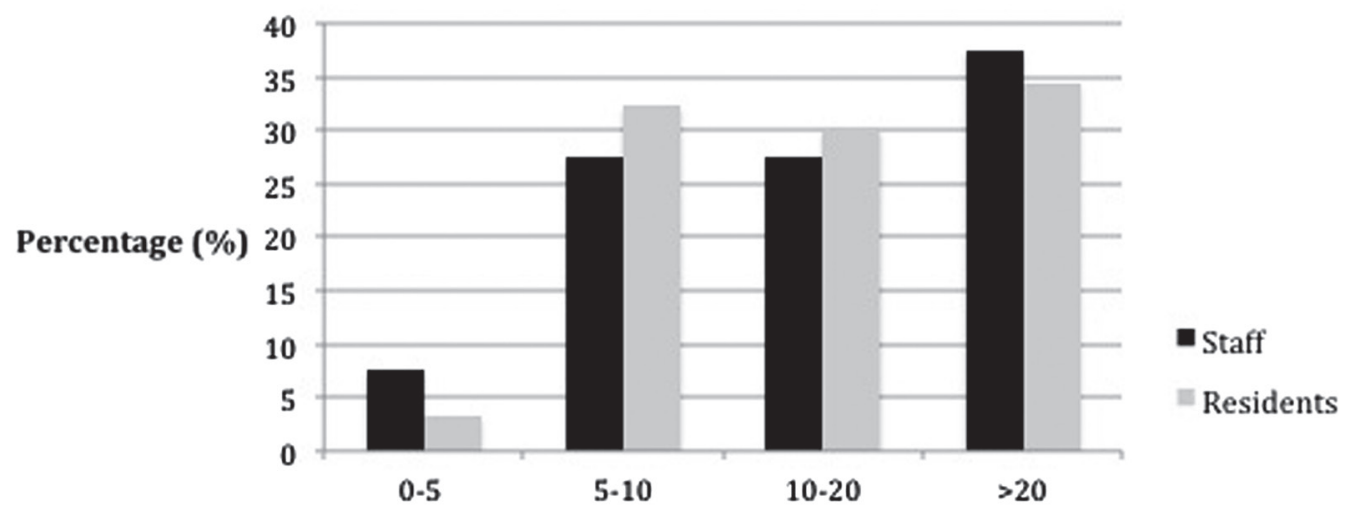

Number of Hours that should be dedicated to PoCUS training

Figure 2. Number of hours that staff and resident should be dedicated to PoCUS Training. 
be included (56\% residents vs. $43 \%$ of staff) while staff thought that arterial line insertion should be a priority (63\% of staff vs. $55 \%$ of residents). Peripheral IV was the least frequently selected procedure by both parties.

Diagnostic applications were also assessed (Figure 4). Focused cardiac ultrasound ( $73 \%$ of staff and $97 \%$ of residents) and Lung Ultrasound ( $68 \%$ of staff and $81 \%$ of residents) were the most commonly selected diagnostic applications.

\section{Discussion}

This is the first needs assessment to examine a Canadian IM program's staff and residents' current practices, comfort and attitudes of PoCUS. It provides valuable insight into the future of PoCUS education and curriculum design in IM residency.

To begin with, both staff and residents felt neutral in their ability to use PoCUS for diagnostic applications. This is consistent with a previous study where IM residents rated their ability to

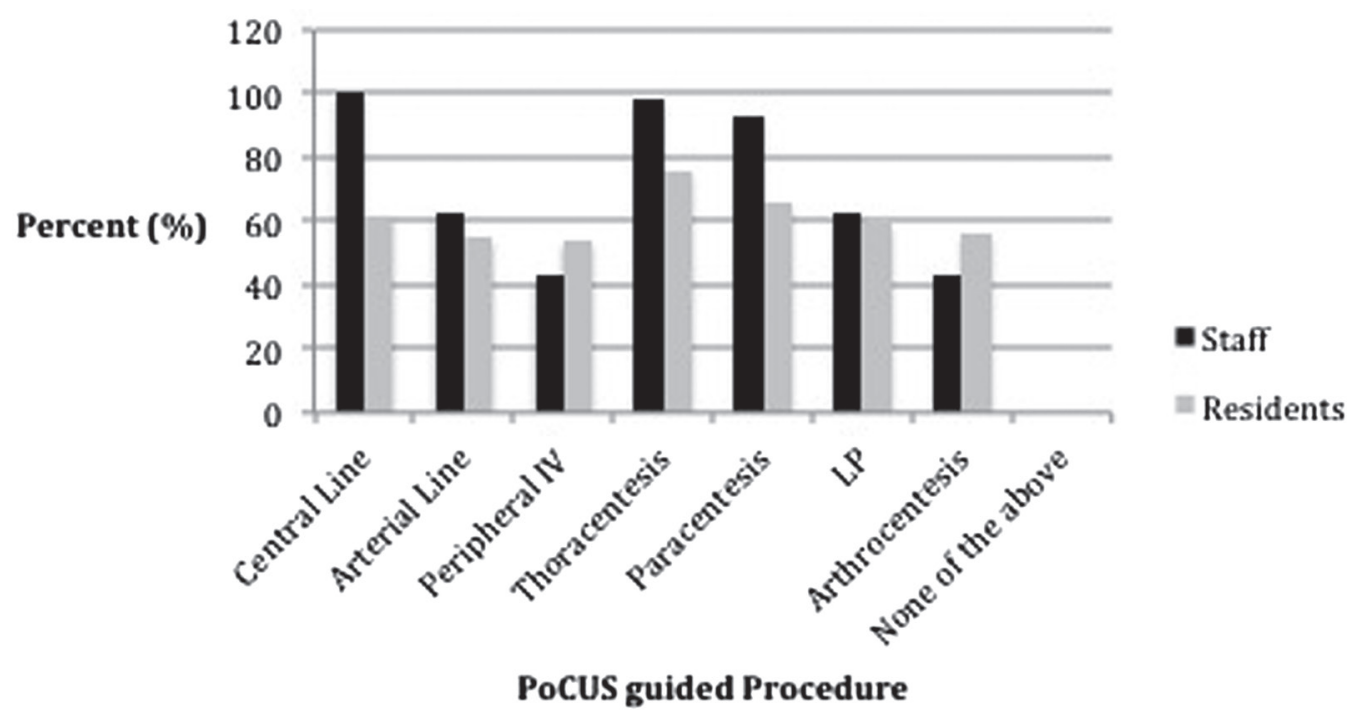

Figure 3. Staff and residents were asked to select the 5 most important PoCUS guided procedures that should be taught to IM residents.

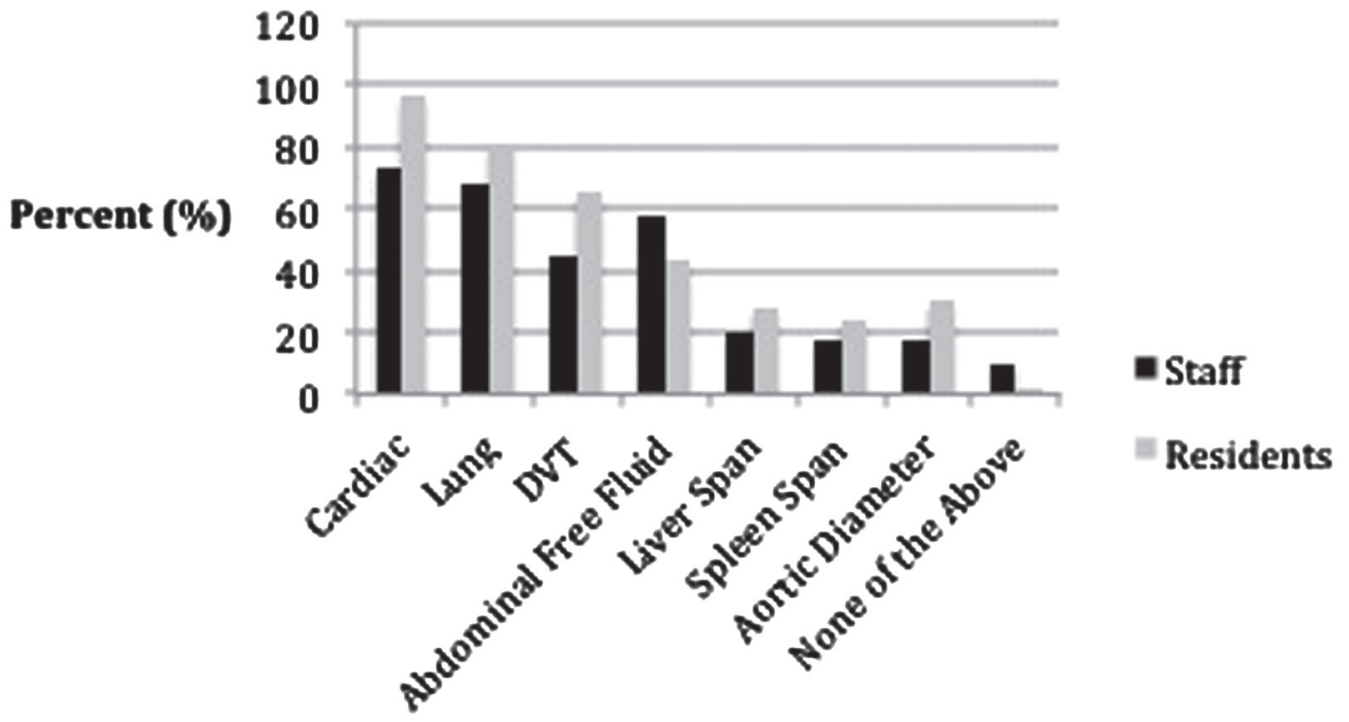

Diagnostic Applications

Figure 4. The most frequently selected diagnostic applications by staff and residents chose focused cardiac ultrasound. 
perform diagnostic tasks using PoCUS between "Somewhat incompetent" and "Neither competent nor incompetent." 13 This lack of competence is most likely attributed to a lack of formal training. Only $9.7 \%$ of residents have received formal training in diagnostic applications. Despite the lack of formal training, one-third of residents are still using PoCUS to help make clinical decisions. The overall lack of formal training highlights a clear learning need. Although this data specifically reflects McMaster, given the relative novelty and new accessibility of PoCUS, other IM residencies should be aware of this potential gap in knowledge and could consider initiating a formal curriculum to ensure eager and naïve adopters of technology act within their scope of care. Several studies conclude that with sufficient training residents may achieve competency. ${ }^{14,24}$ For example, Niendorff et al taught senior medical residents to evaluate cardiac tamponade, hypovolemia and pulmonary embolus using PoCUS during an advanced cardiac life support code, and found that resident acquisition of images and interpretation was adequate and useful. ${ }^{15}$

Both residents and staff agreed that PoCUS should be incorporated into the IM curriculum, making curriculum design the next obvious future step. An experts' consensus on which procedures and diagnostic applications should be taught to Canadian Internal Medicine residents was published in 2014. ${ }^{25}$ The experts felt that central lines (internal jugular and femoral), thoracentesis, paracentesis, joint aspirations and arterial line insertions should be included, which is in keeping with both our staff and resident results. They also stated that peripheral IV insertion and abscess aspirate sampling should be included. Interestingly, both our staff and residents ranked peripheral IV insertion last. US guided IV insertion results in a reduction of complications such as infection, infiltration, artery or nerve injury, hematoma, and line failure. ${ }^{26,27}$ It is also associated with a reduction in number of attempts and patient pain, faster cannulation, and can circumvent the need for central venous catheter placement. ${ }^{27,33}$ Another discrepancy was that the consensus did not recommend introducing ultrasound guided subclavian central line insertion. Central line insertion (internal jugular, femoral and subclavian) was recommended by $100 \%$ of the staff to be taught. A recent Cochrane review found that ultrasound guided subclavian central line insertion significantly reduces hematoma formation and inadvertent arterial punctures. ${ }^{34}$

There were limitations of our study. As aforementioned, this study represents the McMaster IM staff and residents, and cannot be necessarily generalized to other programs with varying amount of PoCUS exposure. A future direction could be to extend the survey across Canada. Also, only $48 \%$ of staff were represented, which could lead to a reporting bias.

\section{Conclusion}

In conclusion, this is the first needs assessment performed in Canada where staff's opinions have been measured. As the use of ultrasound expands in conjunction with the necessity for improved patient safety, there is mounting pressure to educate IM residents in what is becoming a commonplace technology and standard of care. This survey has demonstrated that not only will IM residents use PoCUS to help with clinical decision making despite a lack of formal training, but there is an acceptance by both staff and residents to introduce such a program.

\section{References}

1. Brass P, Hellmich M, Kolodziej L, et al. Ultrasound guidance versus anatomical landmarks for subclavian or femoral vein catheterization. Cochrane Database Syst Rev 2015;1:CD011447. doi: 10.1002/14651858. CD011447.

2. Randolph A, Cook D, Gonzales C. Ultrasound guidance for placement of central venous catheters: a meta-analysis of the literature. Crit Care Med 1994;24:2053-8.

3. Agency for Healthcare Research and Quality. Making health care safer: a critical analysis of patient safety practices. Evidence Report/Technology Assessment: Number 43. AHRQ Publication No. 01-E058. Rockville, MD: Author; 2001.

4. Rizkallah J, Jack M, Saeed M, et al. Non-invasive bedside assessment of central venous pressure: scanning into the future. Plos One 2014.

5. Brennan J, Blair J, Goonewardena S, et al. A Comparison by medicine resident of physical examination versus hand-carried ultrasound for estimation of right atrial pressure. Am J Cardiol 2007;99:1614-6.

6. Eisenberg P, Jaffe A, Schuster G. Clinical evaluation compared to pulmonary catheterization in hemodynamic assessments in critically ill patients. Crit Care Med 1984;12:549-53.

7. Moreno F, Hagan A, Holmen J, et al. Evaluation of size and dynamics of the inferior vena cava as an index of right-sided cardiac function. Am J Cardiol 1984;53:579-85.

8. Canadian Association of Emergency Physicians. Ultrasonography in the emergency department, 1999 Position Statement. Available at: http://caep. $\mathrm{ca} /$ resources/position-statements-and-guidelines/ ultrasonography-ed-1999. Accessed Mar 12, 2012

9. Emergency Department Targeted Ultrasound Interest Group, Canadian Association of Emergency Physicians. Emergency department targeted ultrasound: 2006 update. CJEM 2006;8:170-1.

10. Royal College of Physicians and Surgeons of Canada. Objectives of training in emergency medicine. Available at: http://rcpsc.medical.org/residency/ certification/objectives/emergmed_e.pdf. Accessed Jun 21, 2012.

11. Accreditation Council for Graduate Medical Education. Emergency medicine guidelines. Available at: http://www.acgme.org/acWebsite/RRC_110/110_ guidelines.asp. Accessed Jun 21, 2012.

12. Accreditation Council for Graduate Medical Education. Program requirements for GME in anesthesiology_040_anesthesiology_ 07012014 pdf. Available at: http://www.acgme.org/acgmeweb/portals/0/pfassets/ programrequirements/040_anesthesiology_07012014.pdf. Accessed September 20, 2015

13. Kessler C, Bhandarkar S. Ultrasound training for medical students and internal medicine residents-a needs assessment. J Clin Ultrasound 2010;38:401-8

14. Blaivas M, Fox J. Outcome in cardiac arrest patients found to have cardiac standstill on the bedside emergency department echocardiogram. Acad Emerg Med 2001;8:616-21.

15. Niendorff D, Rassias A, Palac R, et al. Rapid cardiac ultrasound of inpatients suffering PEA arrest performed by nonexpert sonographers. Resuscitation 2005;67:81-7. 
16. Hellmann D, Whiting-O'Keefe Q, Shapiro E, et al. The rate at which residents learn to use hand-held echocardiography at the bedside. Am J Med 2005;118:1010-8.

17. Kobal S, Trento L, Baharami S, et al. Comparison of effectiveness of handcarried ultrasound to bedside cardiovascular physical examination. Am J Cardiol 2005;96:1002-6.

18. DeCara J, Lang R, Koch R, et al. The use of small personal ultrasound devices by internists without formal training in echocardiography. Eur J Echocardiogr 2003;4:141-7.

19. Kimura B, Amundson S, Willis C, et al. Usefulness of a hand-held ultrasound device for bedside examination of left ventricular function. Am J Cardiol 2002;90:1038-9.

20. Ma O, Mateer J, Ogata M, et al. Prospective analysis of a rapid trauma ultrasound examination performed by emergency physicians. J Trauma 1995;38:879-85.

21. Mandavia D, Hoffner R, Mahaney K, et al. Bedside echocardiography by emergency physicians. Ann Emerg Med 2001;38:377-82.

22. Vignon P, Dugard A, Abraha J, et al. Focused training for goal-oriented hand-held echocardiography performed by non-cardiologist residents in the intensive care unit. Intensive Care Med 2007;33:1795-9.

23. Chalumeau-Lemoine L, Baudel J, Das V, et al. Results of short-term training of naïve physicians in focused general ultrasonography in an intensive care unit. Intensive Care Med 2009;35:1767-71.

24. Ojeda J, Colbert J, Lin X, et al. Pocket-sized ultrasound as an aid to physical diagnosis for internal medicine residents: a randomized trail. J Gen Intern Med 2014;30:199-206.

25. The Western Canadian Internal Medicine Ultrasound Curriculum Committee. Expert Consensus on a Canadian Internal Medicine Ultrasound Curriculum. Canadian J of GIM 2014;9:106-11.

26. Roberts J, Hedges J. Clinical Procedures in emergency medicine ( $5^{\text {th }}$ edition). Philadelphia: Elsevier; 2010:385-96.

27. Gillette J, Susini J. Deep brachial vein catheterization for total parenteral nutrition-an alternate approach: review of 154 cases. J Parenter Enternal Nut 1984;8:49-50.

28. Becker B, Helfrich S, Baker E, et al. Ultrasound with topical anesthetic rapidly decreases pain of intravenous cannulation. Acad Emerg Med 2005;12:289-95.

29. Lamperti A, Bodenham M, Pittruti M, et al. International evidence-based recommendations on ultrasound-guided vascular access. Intensive Care Med 2012;38:1105-17.

30. Bauman M, Braude D, Crandall C. Ultrasound-guidance vs. standard technique in difficult vascular access patients by ED technicians. Am J Emerg Med 2009;27:135-40.

31. Costantino T, Parikh A, Satz W, et al. Ultrasonography-guided peripheral intravenous access versus traditional approaches in patients with difficult intravenous access. Ann Emerg Med 2005;46:456-61.

32. Dargin J, Rebholz C, Lowenstein R, et al. Ultrasonography-guided peripheral intravenous catheter survival in ED patients with difficult access. Am J Emerg Med 2010;28:1-7

33. Wu T, Stefanski P. Basic ultrasound-guided procedures. Emergency medicine reports. Practical Jour for Emerg Physic 2011;32:1-6.

34. Brass P, Hellmich M, Kolodziej L, et al. Ultrasound guidance versus anatomical landmarks for subclavian or femoral vein catheterization. Cochrane Database Syst Rev 2015:9:CD011447.

\section{Appendix}

1. What year of training are you currently in?
a. PGY-1
b. PGY-2
c. PGY-3
d. PGY-3
a. PGY-4

2. My current comfort in using PoCUS for clinical assessment and diagnostic application is

a. Extremely uncomfortable

b. Somewhat uncomfortable

c. Neutral

d. Somewhat comfortable

e. Extremely comfortable

3. My current comfort in using PoCUS for procedures is

a. Extremely uncomfortable

b. Somewhat uncomfortable

c. Neutral

d. Somewhat comfortable

e. Extremely comfortable

4. Do you use PoCUS in your daily clinical practice when indicated to help with clinical decisions?

a. No

b. Yes

5. If you haven't used PoCUS in your clinical practice to help with clinical decisions, why not?

a. Not comfortable with image acquisition

b. Not sure how to interpret images

c. No ultrasound available

d. No knowledgeable colleague to review the images with if you are unsure

e. Time constraints

f. N/A-I have used PoCUS

6. I have previously received the following PoCUS training (pelase select all that apply)

\begin{tabular}{|l|l|l|}
\hline & Yes & No \\
\hline Formal training in procedures & & \\
\hline Informal training in procedures & & \\
\hline Formal training in diagnostic application & & \\
\hline Informal training in diagnostic application & & \\
\hline
\end{tabular}

7. If yes, please indicate where and what training you have received

8. For which of the following procedures do you want PoCUS training? (Please select top 5)

a. Central line insertion (internal jugular, femoral and subclavian)

b. Arterial line insertion

c. Peripheral IV insertion

d. Thoracentesis

e. Paracentesis

f. LP

g. Arthrocentesis/joint injections

h. None of the above

i. Other

9. For which of the following PoCUS diagnostic applications do you want training? (Please select top 3)

a. Focused cardiac ultrasound (Including IVC exam, M mode, the parasternal long axis, parasternal short axis, apical and subcostal windows)

b. Lung (including BLUE protocol and examination for pathology such as interstitial syndromes, pneumothorax, consolidation, pulmonary edema and hyperinflation)

c. Deep venous system (A technique to do a quick screen for DVTs)

d. Abdominal free fluid

e. Liver span

f. Spleen span

g. Aortic diameter

h. None of the above

i. Other 


\section{Internal Medicine Residency Training Programs}

10. How much time would you be willing to dedicate per year to formal PoCUS training?
a. 0-5 hours
b. 5-10 hours
c. $10-20$ hours
d. Greater than 20 hours

11. When would you like to have the PoCUS training? (Select all that apply)

a. During academic half days

b. Outside of clinical duty hours in the evenings

c. Outside of clinical duty hours on the weekends

d. I don't want PoCUS training

12. Please read the following stems and indicate your agreement with the statements

\begin{tabular}{|l|l|l|l|l|l|}
\hline & $\begin{array}{l}\text { Strongly } \\
\text { disagree }\end{array}$ & Disagree & Neutral & Agree & Strongly agree \\
\hline $\begin{array}{l}\text { PoCUS is an } \\
\text { important adjunt } \\
\text { to the physical } \\
\text { exam }\end{array}$ & & & & & \\
\hline $\begin{array}{l}\text { Pocus is an } \\
\text { important } \\
\text { tool to use in } \\
\text { procedures }\end{array}$ & & & & & \\
\hline $\begin{array}{l}\text { PoCUS training } \\
\text { should be } \\
\text { introduced in } \\
\text { our internal } \\
\text { medicine } \\
\text { residency } \\
\text { program } \\
\text { curriculum }\end{array}$ & & & & & \\
\hline
\end{tabular}

\begin{tabular}{|l|l|l|l|l|l|}
\hline $\begin{array}{l}\text { PoCUS } \\
\text { improved patient } \\
\text { safety and } \\
\text { outcomes }\end{array}$ & & & & & \\
\hline $\begin{array}{l}\text { I would be } \\
\text { willing to pay for } \\
\text { PoCUS training } \\
\text { outside of the } \\
\text { program }\end{array}$ & & & & & \\
\hline $\begin{array}{l}\text { An informal } \\
\text { OSCE after } \\
\text { the PoCUS } \\
\text { training would } \\
\text { help assess my } \\
\text { competency }\end{array}$ & & & & & \\
\hline
\end{tabular}

13. Who should teach the PoCUS training program?

a. Ultrasound technicians

b. Radiologists/Cardiologists

c. Internal medicine, anesthesia and emergency medicine staff

14. Where do you see PoCUS used in medicine in 10-20 years

a. It will become part of the standard of care for the physical exam and procedures

b. It will be an encouraged adjunct to the physical exam and procedures

c. It will be a completely optional adjunct to the physical exam and procedures

d. PoCUS will not exist in 10-20 years

15. How often do you think there is an opportunity to use PoCUS in your day-

to-day practice?

a. Everyday

b. A few times per week

c. A few times per month

d. A few times per year

e. Never 